\title{
Is the Club Convergence Hypothesis Validy for Turkey Tourism Market
}

\author{
Fatih Kaplan 1,*, Erdoğan Öztürk ${ }^{2} \&$ Şule Güngör ${ }^{3}$ \\ ${ }^{1}$ Department of International Trade and Logistics, School of Applied Technology and \\ Management of Tarsus, Mersin University, Turkey \\ ${ }^{2}$ Karabük University, Demirçelik Campus, Business Administration, Turkey \\ ${ }^{3}$ Department of Accounting and Tax, Vocational School of Tarsus, Mersin University, \\ Turkey \\ *Correspondence: Department of International Trade and Logistics, School of Applied \\ Technology and Management of Tarsus, Mersin University, Turkey. Tel: 90-324-625-45-46 \\ E-mail: fatihkaplan@mersin.edu.tr
}

Received: June 2, 2017 Accepted: August 2, 2017 Published: August 26, 2017

doi: 10.5296/rae.v9i3.11334ＵRL: https://doi.org/10.5296/rae.v9i3.11334

\begin{abstract}
This study empirically revisits and investigates the tourism convergence via using the convergence club algorithm developed by Phillips and Sul (2007: Transition Modeling and Econometric Convergence Tests. Econometrica.75, 1771-1855). Abbott, De Vita and Altinay (2012: Revisiting The Convergence Hypothesis For Tourism Markets: Evidence From Turkey Using The Pairwise Approach. Tourism Management, 33, 537-544.) not to support club convergence hypothesis valid for Turkey tourism market. Yilanci and Eris (2012: Are tourism markets of Turkey converging or not? A Fourier stationary analysis. Anatolia, 23, 207-216) and, Ozcan and Erdogan (2015: Are Turkey's tourism markets converging? Evidence from the two-step LM and three-step RALS-LM unit root. Current Issues in Tourism, 1-18) support convergence hypothesis valid for some Turkey tourism market among countries. Therefore, unlike the findings of previously studies, we submit a club convergence for Turkey.
\end{abstract}

Keywords: Turkey, Tourism Demand, Convergence Hypothesis

Jel Classification: C23, C40, Z30, Z39 


\section{Introduction}

The European Union and the Commonwealth of Independent States (CIS) countries have a significant share in Turkish tourism. In 2014, 53\% of Turkey's visitors came from countries in the European Union and $24 \%$ from CIS countries. Germany was at the top with $14.5 \%$, in 2014. Tourism from Germany increased 1.8 times from 2000 to reach 5.25 million 2014. As Turkey developed relations with CIS countries, visitors from these nations began to hold a prominent place in the Turkish tourism industry. From 1.4 million in 2000, tourism from CIS countries increased 5.4 times to 8.9 million visitors in 2014. The Russian Federation's share in Turkish tourism was 6.5\% (667 000) in 2000, and this increased to $12.1 \%$ in 2014 with 4.48 million visitors (TUIK, 2015). In recent years, the share of EU countries has been decreasing in the Turkish tourism market, while the share of the European Union and CIS countries (particularly Russia), including neighboring countries such as Bulgaria, Iran, Iraq, has been increasing.

Last decades, the Turkey has relied upon tourism receipt more than ever by the reason of developing country. Unfortunately, the economic and the political crises are around the Turkey have affected Turkish tourism demand and Turkish tourism receipt. One hand, the EU countries are a significant partner of tourism receipt of turkey have been affected global economic crises, on the other hand the south neighbor s' of Turkey have been political problems. Therefore, structure of the Turkey tourism demand market has to investigate. The convergence hypothesis is a useful approach in the tourism demand market studies. According to Narayan (2007), there are a number of advantage using convergence analysis when tourism demand market investigates. First, if source markets converging, the tourism policies are successful for this market. Second, we can compare to market whether relatively smaller market is better than larger market. Third, if we have information about that which countries demand are converging, we can use common market strategies.

This study analyzes Turkish tourism demand market via the convergence club algorithm using the Phillips and Sul approach, with annual panel data which belong to 29 countries and cover the period between 1996 and 2014. It is expected that this study will make contribution to the literature in terms of the following points: First of all, we employed Phillips and Sul (2007) approach which, unlike previous studies, can has better performance vis-à-vis the small sample properties of traditional unit root and cointegration tests. Secondly, the data set utilized in the analysis contains twenty nine countries for a long period, 1996-2014, which the time dimension of the panel is long enough to capture long-run trends. Thirdly, although there are various studies upon tourism demand of Turkey, the convergence of tourism market is limited number of studies has been for Turkey.

The paper is organized as follows. In Section 2, the literature is reviewed. The data and econometric methodology are outlined then, the empirical findings are discussed in Section 3. And last, the concluding remarks are provided. 


\section{Literature Review}

There is a vast literature on tourism market but some of causal link remains unclear. There is an increased interest in convergence hypothesis for tourism market. However, this literature seems to be still scarce. In the literature, the first empirical study concerning the convergence hypothesis for tourism market developed by Narayan (2006). In study, he investigated Australia's tourism market was converging by using monthly data. Using unit root tests, he followed a stationary process and examined whether the difference between total visitor arrivals and visitor arrivals from each tourist source market to Australia. According to the estimation results, there is a strong evidence of convergence of Australia's tourism markets. In another study of Narayan (2007), He investigated whether or not Fiji's tourism market was converging and draws similar conclusions for the case of Fiji. The convergence of tourism markets is examined by cointegration process between total visitor arrivals to Fiji and visitor arrivals from each of the eight tourist source markets considered. On the other hand, Lorde and More (2008) investigated the convergence hypothesis for the Carribbean, Lean and Smyth (2008), and Tang (2011) investigated the convergence hypothesis for Malaysia's.

Regarding Turkey, the first empirical study concerning the convergence hypothesis for Turkey tourism markets belongs to Abbott, De Vita and Altinay (2012), who examined whether Turkey's tourism markets are converging. They used the pairwise approach and found that there is no evidence for long-run 'convergence' or 'club convergence' among Turkey's major tourism markets, although most previous studies have found the convergence hypothesis for tourism markets to hold. Abbott et all. asserted that there would be no reason to expect the convergence because of its major source tourist markets have a tendency to gravitate and because of using smaller clusters of tourist source markets grouped according to similar levels of per capita GDP, tourist supply capacity and geographic distance from Turkey.

Yilanci and Zehra (2012), Ozcan and Erdogan (2015), and Hepsag (2015) analyse whether Turkey's major tourist source markets are converging by using monthly data. Yilanci and Zehra (2012) employed the Fourier stationary test and their results reveal that 10 out of 14 markets support the hypothesis of convergence. Ozcan and Erdogan (2015) employed two-step Lagrange multiplier (LM) and three-step residual augmented least squares-Lagrange multiplier (RALS-LM) unit root tests and their results indicate that 10 out of 14 markets are converging too. Merely, Hepsag (2015) investigate the convergence hypothesis of tourism markets in seasonal unit roots framework by taking account of seasonal behaviors of tourist arrivals' differential series. He used the seasonal unit roots test for monthly data of Turkey's 20 major. His results reveal that tourism markets are found to be converging in the long run and in the months of January, March, April, May, July, September, and October, however, the convergence does not valid in the months of February, June, August, and November. 


\section{Data and Methods}

We employ the log t test with the panel of Turkey's 28 major tourist source countries over the period of January 1996-December 2014. The data come from the Turkish Statistical Institute (2015). For all data, we use the Hodrick-Prescott methodology to extract the trend component from the natural logarithms of the series. The countries in the sample are; Austria, Azerbaijan, Belarus, Belgium, Bulgaria, Czech Republic, Denmark, France, Georgia, Germany, Greece, Italy, Israel, Iran, Kazakhstan, Netherlands, Norway, Poland, Russian Federation, Romania, Saudi Arabia, Spain, Sweden, Switzerland, Turkmenistan, UK, Ukraine and the USA.

The study of Phillips and Sul (2007) (hereafter P\&S) allows one to classify state into convergence groups or/and clubs (subgroup). This methodology has several advantage according to other tests. First, the methodology is based on a general nonlinear time-varying factor model that incorporates the possibility of transitional heterogeneity. Second, this methodology can has better performance vis-à-vis the small sample properties of traditional unit root and cointegration tests (Panopoulou and Pantelidis, 2009). Third this methodology is robust to heterogeneity and the stationarity properties of the series. P\&S (2007) considered the following data generation process for a single fact or model:

$$
X_{i t}=g_{i t}+a_{i t}
$$

Equation (1), $X_{i t}$, denote the variable, $\mathrm{N}$ denote to countries $[\mathrm{i}=1, \ldots \mathrm{N}], \mathrm{T}$ denote to time periods $[\mathrm{t}=1, . . \mathrm{T}], g_{i t}$ denotes systematic components and $a_{i t}$ denotes transitory components. We may transform $X_{i t}$ as follow;

$$
X_{i t}=\left(\frac{g_{i t}+a_{i t}}{\mu_{t}}\right) \mu_{t}=\delta_{i t} \mu_{t} \text { for all i and } \mathrm{t}
$$

Where $\mathrm{X}_{\mathrm{it}}$ is decomposed in two components. This components are both of which are time-varying. Where $\delta_{i t}$ idiosyncratic component and where $\mu_{t}$ is common component. $\mathrm{P} \& \mathrm{~S}$ define the relative transition parameter;

$$
h_{i t}=\frac{X_{i t}}{N^{-1} \sum_{i=1}^{N} x_{i t}}=\frac{\delta_{i t}}{N^{-1} \sum_{i=1}^{N} \delta_{i t}},
$$

The loading coefficient is interpreted as the meassure of the transition path of tourism demand of state i relative to the panel average at time t. So, $h_{i t}$ is called relative transition parameter. By the way, in the long run the cross-sectional variance of $h_{i t}$ converges to zero as $\mathrm{t}$ goes to infinite;

$$
\sigma_{t}^{2}=N^{-1} \sum_{i=1}^{N}\left(h_{i t}-1\right)^{2} \rightarrow 0,
$$

Where the null hipothesis implies convergence for all regions, while the alternative implies divergence or club convergence. To test of the null hypothesis;

$$
H_{1}=N^{-1} \sum_{i=1}^{N}\left(h_{i t}-1\right)^{2}
$$




$$
\begin{gathered}
\log \left(H_{1} / H_{t}\right)-2 \cdot \log L(t)=\hat{\alpha}+\widehat{b} \log t+\hat{u}, \\
\text { for } t=[r T],[r T]+1, \ldots T \text { with } \mathrm{r}>0,
\end{gathered}
$$

Where $L(t)=\log (t)$ and $r$ denotes a fraction of the initial sample that is removed prior to ruinning the regression.

\section{Results}

Table 1 reports the result of the panel convergence hypothesis.

Table 1. The Result of Convergence Hypothesis

\begin{tabular}{llll}
\hline & Countries & t-stat & b-coef \\
\hline Full Sample & FULL & -44.804 & -0.129 \\
1st subgroup & Iran, Saudi Arabia, Israel & -3.966 & 1.607 \\
2nd subgroup & Bulgaria, Ukraine, Poland, Kazakhstan, & -2.880 & 2.169 \\
& Turkmenistan & & \\
& Russian Federation, Netherlands, Greece, Sweden, & \\
3nd subgroup & Switzerland, Belgium, Azerbaijan, & -2.469 & 0.097 \\
& Spain, Czech Republic & & \\
4nd subgroup & Germany, France, US, UK, Italy, Austria, Romania, & -2.335 & 2.870 \\
& Denmark & -19.274 & -24.410 \\
\hline
\end{tabular}

The null hypothesis of full convergence is rejected at the level 5\%. The club convergence hypothesis valid for the first subgroup to forth subgroup. While the first row shows the result of full convergence logt test result, the row 2-4 show the result of club clustering algorithm.

Our main finding is that the convergence of Turkey's tourism markets for first subgroup to forth subgroup. Because tourism markets are converging, for these subgroup source markets is not drifting apart. The findings imply that Turkey's tourism strategies are effective.

\section{Conclusion}

This study empirically investigated whether Turkey's tourism demand market are converging via using the convergence club algorithm developed by Phillips and Sul (2007). This findings provide better understanding of Turkey's tourism demand market. Further, our contribution to the literature is that we submit a club convergence for Turkey. 


\section{1) Macrothink}

\section{References}

Abbott, A., De Vita, G., \& Altinay, L. (2012). Revisiting the Convergence Hypothesis for Tourism Markets: Evidence from Turkey Using the Pairwise Approach. Tourism Management, 33(3), 537-44. https://doi.org/10.1016/j.tourman.2011.06.003

Lean, H. H. Smyth, R. (2008). Are Malaysia’s Tourism Markets Converging? Evidence from Univariate and Panel Unit Root Tests with Structural Breaks. Tourism Economics, 14, 97-112.

Lorde, T., \& Moore, W. (2008). Co-Movement in Tourist Arrivals in the Caribbean. Tourism Economics, 14, 631-643.

Narayan, P.K. (2006). Are Australia's Tourism Markets Converging?. Applied Economics, 38(10), 1153-1162. http://dx.doi.org/10.1080/00036840500391377

Narayan, P.K. (2007). Testing Convergence of Fiji's Tourism Markets. Pacific Economic Review, 12(5), 651-663. https://doi.org/10.1111/j.1468-0106.2007.00377

Ozcan, B. S. Erdogan. (2015). Are Turkey's Tourism Markets Converging? Evidence from the Two-step LM and Three-step RALS-LM Unit Root. Current Issues in Tourism, 1-18. http://dx.doi.org/10.1080/13683500.2015.1040741

Panopoulou, E., \& Pantelidis, T. (2009). Club Convergence in Carbon Dioxide Emissions. Environmental Resource $\quad$ Economics, 47, https://doi.org/10.1007/s10640-008-9260-6

Phillips, P. C. B., \& Sul, D. (2007). Transition Modeling and Econometric Convergence $\begin{array}{lll}\text { Tests. } & \text { Econometrica, } & \text { 1771-1855. }\end{array}$ http://korora.econ.yale.edu/phillips/pubs/art/p1216.pdf

Tang, C. F. (2011). Old Wine in New Bottles: Are Malaysia's Tourism Markets Converging?. Asia Pacific Journal of Tourism Research, 16, 263-272. http://dx.doi.org/10.1080/10941665.2011.572661

Yilanci, V., \& Eris, Z. A. (2012). Are Tourism Markets of Turkey Converging or Not? A Fourier Stationary Analysis. Anatolia, 23(2), 207-216. http://dx.doi.org/10.1080/13032917.2012.665010

\section{Note}

This article is revised form of the proceedings of "Are Turkey's Tourism Markets Stable? A Convergence Club Algorithm Approach" presented 17th International Symposium on Econometrics, Operations Research and Statistics 2-4 June 2016, Sivas, Turkey. 


\section{Macrothink}

\section{Copyright Disclaimer}

Copyright for this article is retained by the author(s), with first publication rights granted to the journal.

This is an open-access article distributed under the terms and conditions of the Creative Commons Attribution license (http://creativecommons.org/licenses/by/3.0/). 